\title{
The role of race, sex, hostility, and verbal stimulus in inflicting punishment
}

\section{ZAKHOUR I. YOUSSEF, Eastern Michigan University, Ypsilanti, Mich. 48197}

One hundred and twenty Caucasians selected and administered a variable amount of presumed electric shock to victims (actually Confederates) for verbal errors with the following results: Ss with higher MMPI hostility scores inflicted higher shocks. Male Ss had higher MMPI hostility scores and delivered stronger shocks than females. Male victims received stronger shocks than females. Negro victims received stronger shocks than Whites. Error words with hostile connotations evoked higher shocks than neutral and affectionate words.

This paper adheres to the basic formulation of Berkowitz (1964) that overt aggressive behavior is a joint function of the aggressor's habitual disposition, i.e., internalized and relatively stable personality characteristics and a certain combination of external stimuli. This study is an empirical investigation of how overt aggressive and punitive behavior is affected by two sets of factors: The first set refers to two characteristics of the aggressor, namely his hostility level, as measured by an MMPI-derived scale, and his sex. The second set refers to three characteristics of the victim, namely, his sex, race, and verbal behavior. Overt aggression was measured by the intensity of a presumable electric shock which was selected and administered by Ss to victims (actually Confederates) for the latter's errors, a la Buss $(1961,1963,1966)$ and Brock \& Buss (1964). The verbal behavior of concern was the arousal quality of the error word in the presumed verbal learning experiment.

The first prediction was that Ss with higher hostility scores would inflict a higher shock level. This prediction was based on the assumption that Ss with a higher level of hostility would be more likely to displace their hostility. This also would be a test of the predictive validity of the hostility scale. Previous research in the validation of the various MMPI-hostility scales has led to contradictory results. Positive validation results were obtained by Kaufmann (1966), while failure was reported by Megargee \& Mendelsohn (1962).

The second prediction was that males would inflict a higher level of shock than females. This prediction was based on the results of Brock \& Buss (1964). They found that women had more guilt and inhibition associated with aggression and a higher tendency to overestimate the magnitude of injury than men. Findings by Buss $(1963,1966)$ would lead to expectations of a higher potentiality of aggression in men than women.

The third prediction was that Ss would administer a higher level of shock to a victim of their own sex than to one of the opposite sex. This prediction was based on the assumption that rivalry would be more intense between members of the same sex.

The fourth prediction was that male victims would receive a higher level of shock than female victims. This prediction was based on findings by Buss $(1963,1966)$. Observations outside the laboratory also suggest that males are perceived as physically stronger and, hence, less affected by physical punishment.

The fifth prediction was that Negro victims would receive a higher level of shock than white victims. This prediction was based on the assumption of a higher displacement of aggression to outgroups (Berkowitz, 1962). Since Negroes are often identified with a lower social status, they may also become a more likely target of displaced aggression.

The sixth prediction was that error words with hostile meaning would elicit a higher level of shock than neutral and affectionate words. This prediction was based on the assumption that hostile words would arouse aggressive impulses and phantasies. According to Berkowitz (1964) and Kaufmann (1966) a higher arousal would lead to greater overt aggression.

\section{METHOD}

Two hundred and nine Ss enrolled in Introductory Psychology at Eastern Michigan University participated in the first session as part of that course's requirements. All Ss were group-tested on a scale composed of filler and all non-overlapping items of MMPIderived scales, namely, Cook and Medley's Hostility Scale (1954) and Siegel's Manifest Hostility Scale (1956). The scales were merged to enhance the reliability and predictive validity of self-reported hostility. Excluding the few Negro Ss whose scores were not analyzed, extreme high and low hostility groups for each sex were formed. These extreme and entirely white groups were 56 males and 64 females, with half of each group being High and Low Hostile. Only 120 Ss participated in the subsequent Experimental session.

In the Experimental session, a modified aggression machine (Buss, 1961) was employed for the delivery of an electric shock. A serial list of nine words, run on a Lafayette memory drum, was used as a learning task. Three of these words-Enemy, Murder, and Violence-were assumed to be hostility arousing stimuli; while the words-Table, Radio, and Street-were considered neutral; and Love, Mother, and Child were assumed to be soothing and hostility-inhibiting stimuli. In the S's presence the $E$ read the victim (actually a confederate) standard serial learning instructions with the additional statement that he would receive an electric shock for every error or omission. Then, he read the authentic S a modified version of Buss' (1963) instructions to shock victims for their errors with one of five different intensities.

The victim was programmed to make 30 errors, 10 errors within each emotional level of word categorization. Each error response belonged to the same emotional category as the stimulus that elicited it. Fifteen omissions were interspersed during the first 5 trials. Unknown to Ss, victims were spared the actual shock by a locked switch in the aggression machine. Ss were provided with an identical serial list to insure their recognition of the victim's errors and omissions. Ss were randomly paired with either a white male, white female, a Negro male, or a Negro female victim, with the only restriction of an $N$ of 7 male and 8 female Ss for the 16 independent subgroups generated by victim's sex and race by S's sex and hostility classification.

\section{RESULTS}

A 2 by 2 by 2 by 2 by 3 analysis of variance was conducted on the sum of shock values received for total errors excluding omissions.

The first prediction that Ss with higher hostility scores would inflict a higher level of shock was confirmed. The means were 89.68 and 78.28 for High and Low Hostility groups, respectively. Hostility main effects were significant at the 0.01 level $(F=10.56$, df $=1 / 104)$.

The second prediction that males would inflict a higher shock level than females was supported. The means were 88.27 and 80.25 for males and females, respectively. Main effects of S's sex were significant at the 0.05 level $(F=5.22$, df $=1 / 104)$.

The third prediction that S's sex would interact with victim's sex was not supported. $(F=1.04, \mathrm{df}=1 / 104)$.

The fourth prediction that males would receive a higher shock level than female victims was confirmed. The means were 89.33 and 78.65 for male and female victims, respectively. Main effects of victim's sex were significant at the 0.01 level. $(F=9.24, \mathrm{df}=$ 1/104).

The fifth hypothesis that Negro victims would receive a higher level of shock was supported. The means were 90.03 and 77.94 for Negro and white victims, respectively. Race main effects were significant at the 0.01 level. $(F=11.86, \mathrm{df}=1 / 104)$.

The sixth hypothesis that hostile error words would elicit a higher shock level than neutral and affectionate words was confirmed. The means were $25.54,27.81$, and 30.64 for affec- 
tionate, neutral, and hostile error words, respectively. Main effects of the verbal stimulus were significant at the 0.001 level. $(F=$ 12.26, $\mathrm{df}=2 / 208$ ).

Hostility by S's sex by victim's sex was the only interaction that reached significance at the 0.10 level. $(F=2.92, \mathrm{df}=1 / 104)$. This interaction suggests that highly hostile $S$ s tended to inflict a particularly higher level of shock when the victim belonged to their own sex.

On the hostility scale, males scored significantly higher than females. The means were 35.96 and 27.93 for males and females, respectively. $(\mathrm{t}=3.58, \mathrm{df}=118, \mathrm{p}<.01)$.

\section{DISCUSSION}

This simulation technique demonstrates the role of personality characteristics of the aggressor and stimulus characteristics of the victim in the displacement of hostility and overt aggression. Displacement reaches higher proportions when the aggressor's affective state is hostile due to either a hostile personality disposition or hostile verbal stimuli. Displacement is also stronger either when the victim belongs to a group against which there exist significant prejudices, i.e., Negroes, or to a group considered more capable of enduring physical punishment, i.e., men. It is difficult to ascertain to which degree the victim influences displacement b ecause of perceptual-cognitive factors as compared to modifications in the aggressor's affective state itself.

Having only two victims for each sex and race main effects definitely limits the generalization of these findings. A nested, or a samples within samples design, would have been superior to the present factorial design. For here is a phenomenon which truly fits Brunswik's recommendation (1956) of stimulus sampling.

\section{REFERENCES}

BERKOWITZ, L. Aggressive cues in aggressive behavior and hostility catharsis. Psychological Review, 1964, 71(2), 104-122.

BERKOWITZ, L. Aggression: A social psychological analysis. New York: McGraw-Hill, 1962.

BROCK, T. C., \& BUSS, A. H. Effects of justification for aggression and communication with the victim on postaggression disonance. Journal of Abnormal \& Social Psychology, 1964, 68(4), 403-412.

BRUNSWIK, E. Perception and the representative design of psychological experiments. (2nd ed) Berkeley: University of California Press, 1956.

BUSS, A. H. Instrumentality of aggression, feedback, and frustration as determinants of physical aggression. Journal of Personality \& Social Psychology, 1966, 3(2), 153-162.

BUSS, A. H. The psychology of aggression. New York: Wiley, 1961.

BUSS, A. H. Physical aggression in relation to different frustrations. Journal of Abnormal \& Social Psychology, 1963, 67(1), 1.7.

COOK, W. W., \&MEDLEY, D. M. Proposed hostility and Pharisaic-virtue scales for the MMPI. Journal of Applied Psychology, 1954, 38, 414-418.

KAUFMANN, H. Hostility, perceived similarity and punitivity under arousal conditions. Journal of Personality, 1966, 34(4), 538-545.

MEGARGEE, E. 1., \& MENDELSOHN, G. A. A cross-validation of 12 MMPI indices of hostility and control. Journal of Abnormal \& Social Psychology, $1962,65(6), 431438$.

SIEGEL, S. M. The relationship of hostility to authoritatianism. Journal of Abnormal \& Social Psychology, 1965, 52, 368-372. 